Portland State University

PDXScholar

$5-29-2017$

\title{
Skin in the Game: Voter Preference on the Subject of Bi-Racial Candidate Skin-Tone
}

Daniel A. Vandehey

Portland State University

Follow this and additional works at: https://pdxscholar.library.pdx.edu/honorstheses

Let us know how access to this document benefits you.

\section{Recommended Citation}

Vandehey, Daniel A., "Skin in the Game: Voter Preference on the Subject of Bi-Racial Candidate Skin-Tone" (2017). University Honors Theses. Paper 382.

https://doi.org/10.15760/honors.386

This Thesis is brought to you for free and open access. It has been accepted for inclusion in University Honors Theses by an authorized administrator of PDXScholar. Please contact us if we can make this document more accessible: pdxscholar@pdx.edu. 
Skin in the Game: Voter Preference on the Subject of Bi-Racial Candidate Skin-Tone

Daniel A. Vandehey

Portland State University 


\begin{abstract}
In Caruso et al. (2009), the researchers determine that if a participant liked a bi-racial (one black parent and one white parent) male candidate the participant was more inclined to prefer a photograph of him in which he appears to have a lighter complexion. Caruso et al. explain the results through the lens of a shade-based account of implicit association. This approach does not explore other possible explanations, which presented an opportunity. Therefore, this study extends the research conducted in Caruso et al. (2009) in an attempt to test for the presence or absence of inclusion motivation as a mediating influence between like or dislike of the candidate and preference for a lightened, darkened, or unaltered photograph of the candidate. To pursue this end, one of the three experiments conducted in Caruso et al. (2009) was replicated and executed using participants from a worker pool provided through mTurk.com. This online resource matches human workers to tasks, such as taking surveys, for a small compensation. This participant pool proved unreliable, and the data gathered did not meet the burden of statistical significance. As such, this study can only make comment on some patterns observed in the data and examine areas of the research that could be improved in a future attempt. This study will also examine the significant results in the data gathered for Stern, Balcetis, Cole, West, \& Caruso (2016), which were gathered using the same experiment duplicated for this research, and support the hypotheses presented in this study predicting that light skinned people who like the candidate will more often prefer a lightened photograph, and dark skinned people who like the candidate will more often prefer a darkened photograph.

Keywords: inclusion motivation, shade-based account, race-based account, bi-racial, implicit association
\end{abstract}


Skin in the Game: Voter Preference on the Subject of Bi-Racial Candidate Skin-Tone The Importance of Skin Tone Studies to American Politics

The issue of race and American politics has become more salient with the election of Barack Obama as President of the United States in 2008 and the surprising victory of Donald Trump in 2016. Some optimists saw Obama's victory to become the first black President as an indicator the U.S. could be transitioning into a post-racial society (West, Pearson, Dovidio, Johnson, \& Phills, 2014). Trump's victory was not as auspicious as Obama's. For many, Trump's winning bid for the White House is indicative of an underlying racism in America that was given voice by the candidate's attacks against racial minorities, leaving many minority groups feeling vulnerable to under-representation and discrimination (Allam, 2016). A great deal of ambiguity regarding racial attitudes resides within the United States today, so it is important to determine the motives underpinning today's racial politics. The present research endeavors to contribute to the discourse by centering on racial ambiguity in public office elections and the mediating factors that may influence a voter to choose a Black candidate over a White candidate or vice-versa.

Caruso, Mead, and Balcetis (2009) investigate the role of racial perceptions in public office elections during the 2008 Presidential contest. In a series of three experiments, Caruso et al. manipulate images of a fictitious biracial candidate said to be running for an important position in the U.S. Department of Education, and a factual bi-racial candidate, Barack Obama. In each of the experiments, the researchers alter images of the candidates so each unique pose would have a version in which the skin tone of the candidate was lightened, darkened, and unaltered. Caruso et al. questioned participants to establish their political views, and then the researchers asked participants to select how well each image (three separate poses; one lightened, 
one unaltered, one darkened) "represented" the candidate on a Likert scale anchored at $1=$ not at all, and $7=$ a great deal).

Caruso et al. discovered a significant correlation between agreement or disagreement with a candidate and the participant's preference of skin-tone as the best representation of the candidate. The researchers found that if the participant shared political opinions and ideals with the candidate, she or he was more likely to prefer a picture of the candidate with a lighter skin tone. Caruso et al. explain the results within the confines of the shade-based account for implicit stereotypes, in which dark things are associated with badness and light things are associated with goodness. This explanation circumnavigates the issue of implicit racial bias, chalking the results up to the charming ideas that prompted good cowboys to wear white hats while bad cowboys wear black. In addition to skirting the issue of race in an article about race, Caruso et al. did not consider the motives of the participants, only the subconscious reactions. This study acknowledges that Caruso et al. performed some good science, but perhaps stopped short of determining the true cause of the results gathered. This study attempts to extend the work performed in Caruso et al. to test four hypotheses for the presence or absence of inclusion motivation (a drive to bring a liked outsider into one's in-group) as a mediator between a voter's liking of a candidate and preference of candidate skin-tone.

\section{Literature Review}

\section{The Impact of Biases on Politics}

Whether acting in a manner the perceiver regards as moral and good has any influence over the way in which the perceiver interprets the physical features of others is important considering how vital visual representations are in shaping social interaction (Alter, Stern, Granot, \& Balcetis, 2016). Direct effects of non-verbal cues can be seen in the example of the 
Nixon/Kennedy debate of 1960 (Bailenson, Iyenger, Yee, \& Collins, 2008). Those who listened on the radio felt Nixon had bested Kennedy, but those who watched the televised version felt Kennedy had won the debate. Bailenson and his colleagues argue that Nixon's unattractive appearance compared to Kennedy provided strong, negative non-verbal cues that those listening to the radio could not see. The appearance of a candidate has been deemed important enough in Ecuador and Malawi that photos of the candidates are included on the ballots so that voters who have not been swayed by other factors may render their decision based on the ballot photos alone (Enos, 2016).

Voter reliance on appearance could pose a problem for African-Americans seeking public office, as fictitious black candidates with dark skin-tone received less support than black candidates with lighter skin-tone in a study where all other information regarding the candidates was manipulated to be equal (Hutchings \& Valentino, 2004). In addition, black people in the U.S. who have more prominent prototypical black physical features (e.g., larger lips, wider nose) are less likely to have white friends, more likely to be shot by police while unarmed, and more likely to receive a harsher criminal sentence for a crime than a white person (Alter et al. 2016; Deska, Lloyd, \& Hugenberg, 2016; Mendelberg, 2008; Messing, Jabon, \& Plaut, 2016; Reynolds \& Subasic, 2016; Xiao, Coppin, \& Van Bavel, 2016).

In 2008, accusations that the Hillary Clinton campaign darkened and widened a video of Barack Obama sparked a short-lived scandal (Messing et al., 2016). Accusations flew that the campaign altered to the original video to make Obama appear to have wider features and darker skin. Messing et al. also report that some believed these alterations were intentional to trigger latent stereotypes and cultivate negative attitudes toward Obama. Messing et al. also found that darker images of Obama were frequently used in negative campaign ads during the 2008 
election, especially in ads linking Obama to crime. West et al. (2014) presented participants with an array of photos of Obama. The array included an unaltered photo plus a spectrum of photos in which the skin-tone of Obama had been lightened or darkened. Two times per week, for two weeks leading up to the 2008 election, participants were asked to select the photo they believed was an unaltered picture of the Presidential candidate. Participants then reported for whom they had voted and repeated the photo selection exercise for another two week period immediately following the election. West et al. found correlations between photo selection and voting behavior. Whites who perceived Obama to be darker were less likely to cast a vote for him in the election (West et al., 2014).

Two decades earlier, Terkildson (1993) conducted an experiment where participants read a fictitious profile for a gubernatorial candidate and were then exposed to one of three photos of the candidate. The candidate was represented in the photos as either a white male, a black male with a light complexion, or a black male with a dark complexion. The results clearly demonstrated a disadvantage for both black candidates, and the candidate with the darker skintone was determined to be the least likely to receive votes for the office. Questions administered to determine the explicit racism in subjects failed to make determinations between the attitudes of those who would and those who would not vote for the candidate with the darker complexion (Terkildson, 1993).

The preponderance of evidence indicates the visual representation of a candidate's race is a significant factor considered by citizens when casting their votes. A mix of findings in research concerning race and political elections may indicate the effect on a candidate's race may be subtle (Berinsky, Hutchings, Mendelberg, Shaker, \& Valentino, 2011). Unraveling the causes of this influential bias is a worthy intellectual pursuit. 


\section{Party Affiliation}

The human tendency to use faces as a heuristic for attributes is well established, but other factors, such as party affiliation, must be considered in matters of politics (Enos, 2016). Xiao et al. (2016) claim that people maintain membership in multiple social groups, which can range from the enduring (gender, ethnicity, social class) to the fleeting (school, sports team, sorority). Social Identity Theory and Self-Categorization Theory both posit that people establish and maintain different self-identities depending on which is appropriate for their current context, and thus when the context changes the self-identity, and all the perceptions associated with it, change as well (Reynolds \& Subasic, 2016).

Xiao et al. (2016) believe political identity influenced participants' preference in skin tone regarding the fictitious candidate presented in Caruso et al. (2009), so any experiment testing for skin-tone bias is obligated to control for political alignment.

\section{Race and Participant Pools}

Researchers have struggled to assemble participant pools with meaningful demographic and generalizability properties. When Valentino, Hutchings, and White (2002) included data gathered from black respondents they found the results were consistent with non-blacks, but admit the sample size of black respondents was not sufficient to claim statistical significance. Convenience samples of undergraduate students present problems with generalizability across the voting populace as these young people have little experience with the political process and may be more vulnerable to persuasive campaign communication than the average adult (Valentino et al., 2002). 


\section{Priming and Implicit Association}

Shade-based account. Caruso et al. (2009), regarding the underlying motivation behind skin-tone preference, state, "We expected these biased visual representations to reflect nonconscious associations with skin tone, whereby White is associated with good and Black is associated with bad" (p. 20168). This statement alludes to racial priming in the form of implicit racial stereotypes (Mendelberg, 2008) Alter, Stern, Granot, and Balcetis (2016) propose the shade-based account of association between blackness and danger or evil. In this account, humans are predisposed to think of darkness or blackness as bad due to the darkness of night which was considered to more dangerous than the light of day due to poor visibility giving an advantage to an attacker. Caruso et al. (2009) evoke this model of white equaling good and black equaling bad, but offer little research to back this presumption, nor do they rule out plausible alternatives. Caruso et al. cite Pauker, Weisbuch, Ambady, Sommers, and Adams, Jr. (2009) as a source for the shade-based model, even though Pauker et al. focus on inclusion motivation and describe the shade-based model as an insufficient explanation for the very subject Caruso et al. (2009) address.

Race-based account. A more plausible explanation for the observations recorded in Caruso et al. (2009) is the race-based account, which suggests prejudicial attitudes toward African-Americans are motivated by a desire to maintain racial hierarchies that favor Caucasians (Alter et al., 2016). This model suggests the implicit associations are not between evil and dark colors, but rather evil and dark skin (Arendt, 2013; Berinsky et al., 2011; Correll, Cloutier, \& Mellinger, 2016; Deska et al., 2016; Freeman \& Johnson, 2016; Hutchings \& Valentino, 2004; Leyens \& Yzerbyt, 1992; Gilliam \& Iyenger, 2000; Mendelberg, 2008; Reynolds \& Subasic, 2016; Valentino et al., 2002; West et al., 2014; White, 2007; Xiao et al., 2016). These 
associations can influence decision making, and even though explicitly racist attitudes have seen a decline through the influence of social desirability (Berinsky et al., 2011; Mendelberg, 2008; Valentino et al., 2002), there are still implicit racial attitudes present that people begin acquiring in childhood (Hutchings \& Valentino, 2004). Berinsky et al. (2011) suggest that racial cues are most powerful when they are implicit and avoid the perception of racism.

Research indicates it would be incorrect to assume racial prejudices have disappeared. Instead, they have become more subtle, possibly imperceptible to the person holding the bias (Mendelberg, 2008). Mendelberg states, "Hundreds of studies demonstrate that race cues are primed [emphasis added] by racial stereotypes. Moreover, this literature also makes the specific point critiqued by Huber and Lapinski - that racial cues often work in an implicit way, that is, without awareness" (2008, p. 111). Priming can create associations, such as between the words black and criminal, which reflexively surface when we hear the word black, or the word criminal (Arendt, 2013; Berinsky et al., 2011). In a study, which primed participants by flashing the word "white" or "black" on a screen, the participants were able to identify negative stereotypical words faster after seeing the word "black," and positive stereotypical words faster after seeing the word "white" (Mendelberg, 2008). These surfacing associations are what Arendt (2013) calls automatically activated stereotypes, which can be engaged by recalling the stereotypes as fact whether or not one ever regarded the memories as facts at the time they were learned.

Despite the dubious origins of implicit racial biases, people are more likely to classify a racially ambiguous figure as a black man if said figure is wearing a janitorial uniform, and more likely to classify the same figure as a white man if he is wearing a business suit (Correll et al., 2016; Freeman \& Johnson, 2016). Also, white perceivers believe black men are more muscular and formidable when compared to white men of the same height, weight, and stature (Deska et 
al., 2016). Correll et al. (2016) argue that black targets are often perceived as a larger threat than white targets, and this perception is observed in Blacks and Whites. Correll et al. also argue this perception is driven by pervasive cultural stereotypes. Even Whites who report high egalitarian values may still harbor implicit racial attitudes (West et al., 2014). More surprising, many Blacks also harbor anti-Black implicit biases (White, 2007) Messing et al. (2016) cite an example of black first-graders who were better able to remember stories that portrayed dark skinned characters in a negative manner.

Culture reinforces these stereotypes. Media typically reinforces both hostile and benevolent stereotypes, and exposure to media stereotypes must be studied because of the biases they may create in consumers (Arendt, 2013; Hutchings \& Valentino, 2004; Valentino et al., 2002). Gilliam and Iyenger (2000) conducted an experiment to determine the effect of racial cues in television news. Participants were exposed to one of three conditions in which they viewed a television news story about crime. In one condition the story was accompanied by a picture of a white suspect, the second condition included a picture of a black suspect, and the third condition did not include a picture. Gilliam and Iyengar report, in the condition that did not include a picture, $44 \%$ of the participants claimed to see a picture of a black suspect compared to $19 \%$ who falsely recalled seeing a white suspect. Media reporting of poverty and welfare has become racialized, depicting Blacks as poverty stricken welfare recipients even though this group constitutes a minority of people living in these conditions (Valentino et al., 2002).

As a result of implicit biases, defendants who are black, or who have Afrocentric features, receive harsher prison sentences than white defendants (Reynolds \& Subasic, 2016; Xiao et al., 2016), and black defendants in murder trials are twice as likely to receive death sentences as white defendants (Mendelberg, 2008; Messing et al., 2016). This implicit 
association with Blacks and crime is evident in Mendedberg (2008), where participants identified innocuous items as weapons more often when the person holding the object was AfricanAmerican, and identified weapons as innocuous items more often when the person holding the object was Caucasian. These damaging stereotypical associations can surface in an election, such as the link between terms like "sexually promiscuous" and "too liberal" with Black candidates (Berinsky et al., 2011). Valentino et al. (2002) contend that "Implicit racial priming is inherently manipulative, as it encourages voters to evaluate candidates based on criteria they would likely ignore if they were aware of the intent of the appeal" (p.77). It is this idea that prompted the concern over the negative ads aired by the Clinton campaign (Messing et al., 2016). Reynolds and Subasic (2016) argue that these racial stereotypes grow out of social injustice, and it is not practical to think racial stereotypes can be eradicated before the social injustice issues have been resolved.

Arendt (2013) believes associations of groups with behaviors caused by priming can be cognitively resisted. One form of resistance manifests when stereotyping in the media is so blatant the individual rejects the idea outright. Arendt suggests a second form of resistance is negation, or simply telling oneself, "No! This is not true" (2013, p. 836). Arendt's research supports the claim that negation partially mediates priming effects on implicit stereotypes. When people understand the racial intent of a message, it becomes explicit, and they are better able to suppress priming effects due to motivation to avoid the negative stigma of overt racism (Valentino et al., 2002).

\section{Inclusion Motivation}

Both the shade-based account and race-based account only consider racial priming and implicit racial stereotypes. The concept of New Look encompasses a more perceiver-centric view 
of perception, where understanding the needs, motivations, and expectations of the perceiver are vital to understanding her or his perception (Reynolds \& Subasic, 2016; Xiao et al., 2016). Motives can strongly influence the perception of ambiguous stimuli (Pauker et al., 2009; Stern et al., 2016). Balcetis and Dunning (2006) discovered when presented with an ambiguous symbol that could have been either a letter $B$ or the number 13 , participants more often identified a $B$ when identifying a letter led to drinking an eight-ounce glass of orange juice instead of a foul smelling blended vegetable drink, and 13 when identifying a number led to drinking the orange juice.

Xiao et al. (2016) argue that the need to belong is a fundamental human motive-like the need for food, shelter, and physical well-being — which is fulfilled by the acceptance gained through social affiliations. In most political races, both Blacks and Whites are typically predisposed to voting for someone of their own race, when the option is available, to fulfill the motive of promoting people they feel are representative of their group (Hutchings \& Valentino, 2004). People are motivated to include a person in their group when they feel the person possesses competencies that will advance the standing of the group, and this person's beliefs align with their own (Stern et al., 2016).

Whether people determine others to be like or unlike themselves depends on the individual's perception of the other (Xiao et al., 2016). Xiao et al. report that social psychologists use the term perception to refer to a wide range of processes that extend beyond sensory input and include attributes such as judgment, estimation, and mental representation. "Rather than perceiving the world as it is, people's motives, experiences, and expectations can modify how they experience external stimuli” (Xiao et al., 2016, p. 258). 
When a person has a preconceived notion about what an ambiguous object might be, they will seek out attributes in the object that confirm their bias rather than refute it (Balcetis \& Dunning, 2006). Leyens and Yzerbyt (1992) find that anti-Semitic participants in their study were better able to accurately identify Jewish faces in photographs than non-prejudicial participants. Recent fMRI neuroscience research indicates that the areas of the brain associated with social identity are engaged as quickly as within $100 \mathrm{~ms}$ of visual stimulus, indicating the influence of social identity on the perception and classification of others is almost instantaneous (Xiao et al., 2016).

Swigger (2012) substantiates that voters respond more favorably to candidates whom they perceive to resemble themselves. Voters can identify with candidates based on (among other factors) being of the same race and having similar physical features as the voter (Bailenson et al., 2008). Similarity and familiarity are hard to separate because it is often the things with which we are most familiar are also likely to be similar, such as family (Bailenson et al., 2008). Bailenson et al. suggest that people will give more weight to an argument posed by someone familiar than someone unfamiliar, even when the similarity is so subtle it is unlikely to be consciously perceived.

Bailenson et al. (2008) associate a person's willingness to endorse a candidate who is similar to their race and gender based on the sentiment that the candidate is more likely to have aligned political policies if he or she is similar to the voter in these respects. Swigger (2012) substantiates that the use of images in campaign ads influence voters' perceptions of the candidate's position on issues when the images imply the candidate cares about the voter's ingroup. "Campaign consultants tend to conceive of ads as a way to generate an effective bond 
between the candidate and the electorate by showing viewers that the candidates are "one of them""' (Swigger, 2012, p. 367).

People can surrender a degree of individuality when group identity and belonging are salient, viewing themselves and other in-group members as exemplars of a group with a collective identity (Xiao et al., 2016). When a new person is considered for classification as part of the in-group, part of the decision process must include how this new person will represent the group (Leyens \& Yzerbyt, 1992; Stern et al., 2016). When a person is evaluated and found to be a desirable addition, the in-group members are compelled by an inclusion motivation (Pauker et al., 2009). This motivation can affect in-group members' perception of their target. Stern et al. (2016) found that when participants agreed with the positions of the political candidate they were more likely to assign the candidate physical features that more resembled their own, and less likely to make the same assignments when participants disagreed with the candidate.

This phenomenon works in an inclusive and exclusive manner. Xiao et al. (2016) suggest that on an instinctual level, protecting the in-group from out-group threats may have held a survival advantage at some point in human evolution. Leyens and Yzerbyt (1992) coin the term in-group overexclusion to describe a group's tendency to reject ambiguous out-group members so as not to contaminate the group with misidentified group members. Pauker et al. (2009) argue that when a bi-racial person's features appear atypical for a race, perceivers within that race will treat the person like any other out-group member. A group's collective identity can also affect biases in memory, leading to influence over behavior and the evaluation of others (Xiao et al., 2016). This identity often leads to discrimination against members of out-groups over superficial differences, such as race. Messing et al. (2016) state, "Whites maintain more negative 
associations with Blacks than ingroup members, and this was particularly so for Blacks with more prototypical features, including darker skin" (p. 46).

\section{Hypotheses}

Social Identity Theory defines inclusion motivation as the desire to include a liked other in one's in-group while excluding others who are not liked. Within this theoretical framework, it is possible that desire to include or exclude a racially ambiguous candidate in the voter's racial in-group may influence how the voter perceives the skin-tone of the candidate (Pauker et al., 2009). This aspect of Social Identity Theory prompts questions regarding the motives behind skin tone preferences that are not addressed in the research conducted in Caruso et al. (2009), which is why the present study will seek to extend the research performed by Caruso and his colleagues. In this pursuit, the present research will attempt to support the following hypotheses.

H1: Caucasian voters who agree with the political platform of a racially ambiguous candidate are more likely to believe an image of the candidate with lighter skin is a better representation of the candidate.

H2: Caucasian voters who disagree with the political platform of a racially ambiguous candidate are more likely to believe an image of the candidate with darker skin is a better representation of the candidate.

H3: Non-Caucasian voters who agree with the political platform of a racially ambiguous candidate are more likely to believe an image of the candidate with darker skin is a better representation of the candidate.

H4: Non-Caucasian voters who disagree with the political platform of a racially ambiguous candidate are more likely to believe an image of the candidate with lighter skin is a better representation of the candidate. 


\section{Methods}

The claim that skin tone preference is the result of inclusion motivation cannot be substantiated without the introduction of new data. Caruso et al. (2009) discarded demographic data, including ethnicity data, in the final analysis as it was determined to be irrelevant. If the sample for the three experiments consists predominantly of one race, this is a valid omission. This study endeavors to extend the valuable research conducted in Caruso et al. (2009) to include a sample with a balance of participants who identify as Caucasian and Non-Caucasian, and a comparison of responses to test for the presence of inclusion motivation. This comparison will be accomplished through the replication of the first experiment detailed in Caruso et al. (2009), attempting to change only the recruitment with the aim of gathering and documenting a significant sample of Non-Caucasian respondents.

\section{Participants}

Participants were recruited through mTurk.com, an internet service that matches human workers to tasks, such as the completion of surveys, in exchange for a small compensation. Participants received $\$ 0.50$ for completing an online survey hosted by Qualtrics.com. Initial responses resulted in 345 completed surveys $(\mathrm{N}=345)$. Approximately $35 \%(\mathrm{n}=120)$ of the responses were removed from the data. Approximately $10 \%(\mathrm{n}=34)$ of the responses were submitted by duplicate users, $2 \%(\mathrm{n}=7)$ were submitted by workers took longer than 20 minutes to complete the survey, and 23\% $(\mathrm{n}=79)$ raced through the survey (completed survey in less than 166 seconds, which constitutes the first quartile relative to completion time). The total number of number of responses considered in the analysis $(\mathrm{N}=225)$ was comprised of $60 \%$ male respondents $(\mathrm{n}=137), 39 \%$ female $(\mathrm{n}=87)$, and $1 \%$ identifying as "Other" $(\mathrm{n}=1)$. Ethnicity was comprised of $8 \%$ African American/Black $(\mathrm{n}=18), 1 \%$ American Indian $(\mathrm{n}=2), 14 \%$ 
Asian $(n=31), 68 \%$ Caucasian/White $(n=153), 2 \%$ Indian $(n=5), 5 \%$ Latino/Latina $(n=12)$, and $2 \%$ identifying as "Other" $(\mathrm{n}=4)$.

\section{Measures}

Participants completed an online survey that was composed to replicate the survey used in Experiment \#1 in Caruso et al. (2009)(see Appendix for full survey details). The experiment built around the survey is a $2 \mathrm{X} 2 \mathrm{X} 3$ design, including two participant pools (Caucasian and NonCaucasian), two conditions (candidate supports respondent's policy views, and candidate rejects respondent's policy views), and the rating of three stimuli (photograph of candidate with skintone: 1) darkened $15 \%, 2$ ) unaltered, and 3) lightened 15\%). Respondents were primed with a backstory regarding a fictitious candidate, Dr. Michael Barnes, who is currently exploring the viability of a campaign for an open seat on the United States Department of Education. The story includes a brief history of Barnes's parents, a bi-racial couple who met in college and later married. Following a short overview of Barnes's accomplishments, respondents are instructed to indicate an answer of "agree" or "disagree" after reading six statements regarding education policy in the United States. Five of the six statements are designed to be relevant to a wide range of respondents, and include, "The amount of time public schools are in session during a given year is too little, and the school year must be lengthened to improve the quality of American public education." One of the six statements, "Administration deadlines should be coordinated nationally instead of being left to the discretion of each state," is designed to have little or no relevance to respondents.

After responding to the six statements, the respondents are exposed to one of two conditions. In both conditions, the candidate's position on each of the six statements is revealed. In condition one, the candidate agrees with the respondent on the five relevant statements and 
disagrees with the one irrelevant statement. In condition two, the candidate disagrees with the respondent on the five relevant statements and agrees on the one irrelevant statement. This manipulation is designed to prime respondents with a like or dislike of the candidate. In both conditions, the respondent is then asked to rate three different pictures based on the following criteria: "Please assess each picture on its suitability to represent Dr. Barnes as a candidate for the U.S. Department of Education. You will rate the photos on a scale from Strongly Agree (the picture represents Dr. Barnes very well) to Strongly Disagree (the picture does not represent Dr. Barnes well at all)." Responses were recorded on a seven-point Likert scale anchored at $1=$ Strongly Agree and $7=$ Strongly Disagree. The scale was inverted in the analysis, so it was anchored at $1=$ Strongly Disagree and $7=$ Strongly Agree to facilitate consistency between the present study and Caruso et al. (2009).

\section{Results}

None of the data gathered meet the burden of statistical significance. This section reports the analysis of the data gathered but makes no claim of significance. Data was categorized by ethnicity, and include Aggregate (all ethnicities), Caucasian, and Non-Caucasian. All categories of data were examined for Condition 1 (candidate supports respondent's policy views) and Condition 2 (candidate rejects respondent's policy views).

\section{Aggregate, Condition 1 (policies supported)}

The sample was comprised of 121 participants $(\mathrm{N}=121), 62 \%$ male $(\mathrm{n}=75), 37 \%$ female $(n=45)$, and $1 \%$ identifying as "Other" $(n=1)$. Ethnicity was comprised of $6 \%$ African American/Black $(n=7), 12 \%$ Asian $(n=15), 71 \%$ Caucasian/White $(n=86), 2 \%$ Indian $(n=2)$, $7 \%$ Latino/Latina $(\mathrm{n}=9)$, and 2\% identifying as "Other" $(\mathrm{n}=2)$. Analysis of Data (ANOVA) with an alpha of .05 revealed the data to be statistically insignificant $(p=.25)$. Participants 
preferred the lightened photograph $(M=5.55, S D=1.41)$, followed by the unaltered photograph $(M=5.33, S D=1.45)$, and lastly the darkened photograph $(M=5.22, S D=1.56)$.

\section{Aggregate, Condition 2 (policies rejected)}

The sample was comprised of 104 participants $(\mathrm{N}=104), 60 \%$ male $(\mathrm{n}=62)$, and $40 \%$ female $(n=42)$. Ethnicity was comprised of $11 \%$ African American/Black $(n=11), 2 \%$ American Indian $(n=2), 15 \%$ Asian $(n=16), 71 \%$ Caucasian/White $(n=86), 3 \%$ Indian $(n=3)$, $3 \%$ Latino/Latina $(\mathrm{n}=3)$, and $2 \%$ identifying as "Other" $(\mathrm{n}=2)$. ANOVA with an alpha of .05 revealed the data to be statistically insignificant $(p=.40)$. Participants preferred the unaltered photograph $(M=5.11, S D=1.55)$, followed by the darkened photograph $(M=5.09, S D=1.51)$, and lastly the lightened photograph $(M=4.85, S D=1.55)$.

\section{Caucasian, Condition 1 (policies supported)}

The sample was comprised of 86 Caucasian participants $(N=86), 63 \%$ male $(n=54)$, $36 \%$ female $(n=31)$, and $1 \%$ identifying as "Other" $(n=1)$. ANOVA with an alpha of .05 revealed the data to be statistically insignificant $(p=.09)$. Participants preferred the unaltered photograph $(M=5.69, S D=1.31)$, followed by the lightened photograph $(M=5.29, S D=1.50)$, and lastly the darkened photograph $(M=5.22, S D=1.66)$.

\section{Caucasian, Condition 2 (policies rejected)}

The sample was comprised of 67 Caucasian participants $(\mathrm{N}=67), 57 \%$ male $(\mathrm{n}=38)$, and $43 \%$ female $(n=29)$. ANOVA with an alpha of .05 revealed the data to be statistically insignificant $(p=.42)$. Participants preferred the darkened photograph $(M=5.19, S D=1.49)$, and the unaltered photograph $(M=5.19, S D=1.56)$ equally, followed by the lightened photograph $(M=4.90, S D=1.50)$.

\section{Non-Caucasian, Condition 1 (policies supported)}


The sample was comprised of 35 participants $(\mathrm{N}=35), 60 \%$ male $(\mathrm{n}=21)$, and $40 \%$ female $(n=14)$. Ethnicity was comprised of $20 \%$ African American/Black $(n=7), 43 \%$ Asian $(n$ $=15), 6 \%$ Indian $(n=2), 26 \%$ Latino/Latina $(n=9)$, and $6 \%$ identifying as "Other" $(n=2)$. ANOVA with an alpha of .05 revealed the data to be statistically insignificant $(p=.76)$. Participants preferred the lightened photograph $(M=5.43, S D=1.31)$, followed by the darkened photograph $(M=5.23, S D=1.31)$, and lastly the unaltered photograph $(M=5.20, S D=1.59)$.

\section{Non-Caucasian, Condition 2 (policies rejected)}

The sample was comprised of 37 participants $(\mathrm{N}=37), 65 \%$ male $(\mathrm{n}=24)$, and $35 \%$ female ( $\mathrm{n}=13)$. Ethnicity was comprised of $30 \%$ African American/Black $(\mathrm{n}=11), 5 \%$ American Indian $(n=2), 43 \%$ Asian $(n=16), 8 \%$ Indian $(n=3), 8 \%$ Latino/Latina $(n=3)$, and $5 \%$ identifying as "Other" $(\mathrm{n}=2)$. ANOVA with an alpha of .05 revealed the data to be statistically insignificant $(p=.87)$. Participants preferred the unaltered photograph $(M=4.95, S D$ $=1.54)$, followed by the darkened photograph $(M=4.89, S D=1.54)$, and lastly the lightened photograph $(M=4.76, S D=1.66)$.

\begin{tabular}{|c|c|c|c|c|c|c|c|c|c|c|c|c|}
\hline & \multicolumn{4}{|c|}{ Aggregate } & \multicolumn{4}{|c|}{ Caucasian } & \multicolumn{4}{|c|}{ Non-Caucasian } \\
\hline & \multicolumn{2}{|c|}{$\begin{array}{c}\text { Policies } \\
\text { Supported }\end{array}$} & \multicolumn{2}{|c|}{$\begin{array}{l}\text { Policies } \\
\text { Rejected }\end{array}$} & \multicolumn{2}{|c|}{$\begin{array}{c}\text { Policies } \\
\text { Supported }\end{array}$} & \multicolumn{2}{|c|}{$\begin{array}{l}\text { Policies } \\
\text { Rejected }\end{array}$} & \multicolumn{2}{|c|}{$\begin{array}{c}\text { Policies } \\
\text { Supported }\end{array}$} & \multicolumn{2}{|c|}{$\begin{array}{l}\text { Policies } \\
\text { Rejected }\end{array}$} \\
\hline & $M$ & $S D$ & $M$ & $S D$ & $M$ & $S D$ & $M$ & $S D$ & $M$ & $S D$ & $M$ & $S D$ \\
\hline Lightened & 5.33 & 1.45 & 4.85 & 1.55 & 5.29 & 1.50 & 4.90 & 1.50 & 5.43 & 1.31 & 4.76 & 1.66 \\
\hline Darkened & 5.22 & 1.56 & 5.09 & 1.51 & 5.22 & 1.66 & 5.19 & 1.49 & 5.23 & 1.31 & 4.89 & 1.54 \\
\hline nalte & 5.55 & 1.41 & 5.11 & 1.55 & 5.69 & 1.31 & 5.19 & 1.56 & 5.20 & 1.59 & 4.95 & 1.54 \\
\hline
\end{tabular}

Table 1. Response distribution regarding extent of agreement with the representativeness of candidate photographs that have been lightened, darkened, or unaltered. Likert seven point scale 
anchored at $1=$ Strongly Disagree and $7=$ Strongly Agree . Results statistically insignificant $(p>$ $.05)$.

\begin{tabular}{|c|c|c|c|c|}
\hline & \multicolumn{2}{|c|}{ Caruso et al. (2009)* } & \multicolumn{2}{|c|}{ Aggregate $(\mathrm{N}=225) * *$} \\
\hline & $\begin{array}{c}\text { Share's } \\
\text { candidate's } \\
\text { views, \% }\end{array}$ & $\begin{array}{c}\text { Opposes } \\
\text { candidate's } \\
\text { views, \% }\end{array}$ & $\begin{array}{c}\text { Share's } \\
\text { candidate's } \\
\text { views, \% }\end{array}$ & $\begin{array}{c}\text { Opposes } \\
\text { candidate's } \\
\text { views, \% }\end{array}$ \\
\hline Lightened & 25 & 11 & 13 & 13 \\
\hline Darkened & 10 & 26 & 17 & 18 \\
\hline Unaltered & 15 & 19 & 18 & 17 \\
\hline \multirow[t]{3}{*}{ Tied } & 50 & 44 & 52 & 52 \\
\hline & \multicolumn{2}{|c|}{ Caucasian $(\mathrm{N}=153) * *$} & \multicolumn{2}{|c|}{ Non-Caucasian $(\mathrm{N}=72) * *$} \\
\hline & $\begin{array}{c}\text { Share's } \\
\text { candidate's } \\
\text { views, \% }\end{array}$ & $\begin{array}{c}\text { Opposes } \\
\text { candidate's } \\
\text { views, \% }\end{array}$ & $\begin{array}{c}\text { Share's } \\
\text { candidate's } \\
\text { views, \% }\end{array}$ & $\begin{array}{c}\text { Opposes } \\
\text { candidate's } \\
\text { views, \% }\end{array}$ \\
\hline Lightened & 12 & 12 & 17 & 14 \\
\hline Darkened & 16 & 18 & 17 & 19 \\
\hline Unaltered & 24 & 15 & 3 & 22 \\
\hline Tied & 48 & 55 & 63 & 46 \\
\hline
\end{tabular}

$* \mathrm{p}<.001$

$* * \mathrm{p}>.05$ (statistically insignificant)

Table 2. Percentages of preference across categories compared with findings from Caruso et al. (2009).

\section{Discussion}

The data gathered for this study proves problematic in that it is statistically insignificant from the perspective of both probability and a significant number of responses the NonCaucasian categories. This following discussion examines the data against the hypotheses to see if the predicted outcomes are observed, but this discussion does not imply the results are statistically significant.

Hypothesis 1 predicts that Caucasian voters who agree with the political platform of a racially ambiguous candidate are more likely to believe an image of the candidate with lighter 
skin is a better representation of the candidate. This hypothesis is not supported. Though participants marginally preferred a lightened photograph $(M=5.29, S D=1.50)$ over a darkened photograph $(M=5.22, S D=1.66)$, the most preferred photographs were unaltered $(M=5.69, S D$ $=1.31)$.

Hypothesis 2 predicted that Caucasian voters who disagree with the political platform of a racially ambiguous candidate are more likely to believe an image of the candidate with darker skin is a better representation of the candidate. This hypothesis is not supported. Though participants preferred a darkened photograph $(M=5.19, S D=1.49)$ over a lightened photograph $(M=4.90, S D=1.50)$, the unaltered photographs $(M=5.19, S D=1.56)$ tied with the darkened photographs for preference.

Hypothesis 3 predicts that Non-Caucasian voters who agree with the political platform of a racially ambiguous candidate are more likely to believe an image of the candidate with darker skin is a better representation of the candidate. This hypothesis is not supported. Participants preferred a lightened photograph $(M=5.43, S D=1.31)$ over a darkened photograph $(M=5.23$, $S D=1.31)$, or an unaltered photograph $(M=5.20, S D=1.59)$.

Hypothesis 4 predicts that Non-Caucasian voters who disagree with the political platform of a racially ambiguous candidate are more likely to believe an image of the candidate with lighter skin is a better representation of the candidate. This hypothesis is not supported. Participants preferred an unaltered photograph $(M=4.95, S D=1.54)$ over a darkened photograph $(M=4.89, S D=1.54)$, or a lightened photograph $(M=4.76, S D=1.66)$.

The data does not achieve parity with the results recorded for in Caruso et al. (2009). Analysis of the aggregate responses in this study should have yielded similar results to the first experiment conducted in the original research. Where Caruso et al. recorded a distinct preference 
for a lightened photo when participants believed the candidate supported their policy views (25\% vs. $11 \%$ who believed the candidate rejected their policy views), and recorded a distinct preference for a darkened photo when participants believed the candidate rejected their policy views ( $26 \%$ vs. $10 \%$ who believed the candidate supported their policy views), the present research recorded no significant difference between conditions and preferences.

Had the data passed statistical scrutiny, it would not have supported any of the hypotheses or achieved parity with the research it is extending. This lack of support indicates one of two possibilities. One, the hypotheses are invalid and would be unsupported by credible data. Two, the hypotheses may be valid, but the experiment was flawed on one or more levels. I believe it is the latter explanation rather than the former. The reason I hold this opinion has much to do with a discovery I made after my data collection and analysis were complete.

As I was gathering additional literature for this study, I found an article buried under four pages of results on a Social Science Citation Index search for articles citing Caruso et al. (2009). The research I found in Stern et al. (2016) extends the first experiment in Caruso et al. (2009) with the help of Caruso ( $4^{\text {th }}$ author) and Balcetis ( $2^{\text {nd }}$ author). There were a few differences in the way the experiment was conducted (even the photographs were the same), but there were no differences that would render the experiment invalid for the present study. The chief difference is recruitment. Stern et al. (2009) were able to recruit 57 black participants and compare results from this pool against a pool of 98 white participants. ANOVA reveals their data are statistically significant $(p<.05)$.

Stern et al. (2016) found that Whites who believed the candidate supported their policy views preferred a lightened photograph $(\mathrm{M}=5.16, \mathrm{SD}=1.01)$ over a darkened photograph $(\mathrm{M}=$ 4.51, $\mathrm{SD}=1.57$ ), and Whites who believed the candidate rejected their policy views marginally 
preferred a darkened photograph $(M=4.23, S D=1.59)$ over a lightened photograph $(M=4.14$, $\mathrm{SD}=1.60)$. Blacks who believed the candidate supported their policy views preferred a darkened photograph $(\mathrm{M}=5.46, \mathrm{SD}=1.04)$ over a lightened photograph $(\mathrm{M}=4.79, \mathrm{SD}=1.29)$, and Blacks who believed the candidate rejected their policy views marginally preferred a lightened photograph $(M=4.83, S D=1.69)$ over a darkened photograph $(M=4.00, S D=1.98)$. These results support all four hypotheses posited in the present study.

\begin{tabular}{|c|c|c|c|c|c|c|c|c|}
\hline & \multicolumn{4}{|c|}{ Caucasian } & \multicolumn{4}{|c|}{ African-American } \\
\hline & \multicolumn{2}{|c|}{$\begin{array}{c}\text { Policies } \\
\text { Supported }\end{array}$} & \multicolumn{2}{|c|}{$\begin{array}{l}\text { Policies } \\
\text { Rejected }\end{array}$} & \multicolumn{2}{|c|}{$\begin{array}{c}\text { Policies } \\
\text { Supported }\end{array}$} & \multicolumn{2}{|c|}{$\begin{array}{l}\text { Policies } \\
\text { Rejected }\end{array}$} \\
\hline & $M$ & $S D$ & $M$ & $S D$ & $M$ & $S D$ & $M$ & $S D$ \\
\hline Lightened & 5.16 & 1.01 & 4.14 & 1.60 & 4.79 & 1.29 & 4.83 & 1.69 \\
\hline Darkened & 4.51 & 1.57 & 4.23 & 1.59 & 5.46 & 1.04 & 4.00 & 1.98 \\
\hline Unaltered & 4.93 & 1.26 & 4.58 & 1.44 & 4.82 & 1.22 & 4.76 & 1.92 \\
\hline
\end{tabular}

Table 1. (data from Stern et al. (2016)) Response distribution regarding the extent of agreement with the representativeness of candidate photographs that have been lightened, darkened, or unaltered. Likert seven-point scale anchored at $1=$ Strongly Disagree and $7=$ Strongly Agree . Results statistically significant $(p<.05)$.

\section{Conclusion}

Since Stern et al. (2016) gathered data in another study utilizing a nearly identical copy of the experiment used in this study, one must conclude there were problems with the experiment's construction and execution. Examination of the experiment used in the present study, compared to the experiment described in Stern et al. (2016), indicate there were a few differences worth an examination.

In Stern et al.(2016), once participants responded to the six statements regarding education policy they were explicitly notified that either the candidate disagreed with them only 
on the issue of administration deadlines (the irrelevant statement) or agreed with them only on the issue of administration deadlines. In this study's experiment, there was no such explicit notification. The survey was constructed to list the candidate's positions, which would largely support or reject the participant's positions, but it did not signify whether the candidate agreed or disagreed with the participant. If a participant was paying minimal attention, it would be more difficult in this study's experiment to determine, as a participant, whether the candidate was in agreement. Since the data gathered indicates the participants in this experiment were not primed to like or dislike the candidate, the design of the Stern et al. experiment was likely superior.

Stern et al. (2016) used online ads on Facebook and Craigslist to drive participant traffic to the survey. Participants were paid $\$ 5.00$ to complete the survey, compared to the $\$ .50$ paid to mTurk workers who participated in this study's survey. The incentive offered provided for more reliable data $(\mathrm{p}<.05)$ and a participant pool with $37 \%$ black respondents. Attempting to use mTurk.com to supply participants for this study's survey must be classified as a grave error. The workers on mTurk.com demonstrated very little care and quality in their work. Time trials conducted before launching the survey indicated a minimum of four minutes was necessary to read all content except the informed consent and debriefing pages, which I assumed workers would not read. Approximately 50\% $(n=170)$ of the respondents completed the survey in under four minutes. I was forced to keep nearly a hundred responses completed between 2 minutes, 46 seconds and 4 minutes so I would have enough data to attempt some form of meaningful analysis. From the perspective of the mTurk worker, it makes no sense to do a comprehensive job of filling out one survey when the worker can triple her or his income by racing through three surveys in the same amount of time. 
Efforts in this study to recruit balanced pools of Caucasian and Non-Caucasian (I was originally trying to recruit equal numbers of Blacks and Whites) were unsuccessful. I employed the help of a professional software engineer who wrote a Python script which he integrated with mTurk.com. The script pre-qualified workers and gave them access to either a survey for black respondents or white respondents depending on how the worker answered the prequalification question. If the worker was neither Caucasian nor African-American, the worker was excluded from the survey. The script worked very well, but the low pay associated with the extra trouble enticed only three white respondents and zero black respondents over a twenty-four hour period. Failure to acquire the ideal participant pools required a compromise in which the hypotheses were reworded to replace the term "African-American" with "Non-Caucasian."

This experiment would have benefitted from some other measures not mentioned in Stern et al. (2016). A question within the survey that would have tested to make sure the respondent was paying attention would have been helpful and would have contributed to an efficient process for accepting and rejecting work. Also, the resolution of the photographs secured for the survey was low, and alterations to the color of the isolated skin areas caused the lightened photos to look unnatural. In addition, the subject in the photo had predominantly Afrocentric features, which compounded issues with the unnatural look of the lightened photos. A future attempt would require securing better quality photographs of a subject with ambiguous features in addition to ambiguous skin-tone.

Though the results of this study are disappointing, there is some consolation in the fact Stern et al. (2016) were able to avoid some costly missteps and conduct largely the same experiment with results that suggest the hypotheses presented in this study have some merit. The importance of this study and others like it is obviated by the unpredictability of the 2016 
Presidential race, which, for many, was driven by latent racial attitudes (Allam, 2016). There is peril in the oversimplification of voting motives, and it is vital that examination of motives, especially racially driven motives, continue as a prominent scholarly pursuit. 


\section{References}

Alter, A.L., Stern, C., Granot, Y., \& Balcetis, E. (2016). The "bad is black" effect: Why people believe evildoers have darker skin than do-gooders. Personality and Social Psychology Bulletin, 42(12), 1653-1665. DOI: 10.1177/0146167216669123

Allam, H. (2016). Many minorities see Trump's win as a victory for white supremacy. McClatchyDC, November 9, 2016, Retrieved from http://www.mcclatchydc.com/news/politics-government/election/article113795063.html

Arendt, F. (2013). Dose-dependent media priming effects of stereotypic newspaper articles on implicit and explicit stereotypes. Journal of Communication, 63(5), 830-851. doi:10.1111/jcom.12056

Bailenson, J.N., Iyenger, S., Yee, N., \& Collins, N.A. (2008). Facial similarity between voters and candidates causes influence. Public Opinion Quarterly. 72(5). 935-961.

Balcetis, E., \& Dunning, D. (2006). See what you want to see: Motivational influences on visual perception. Journal of Personality and Social Psychology, 91, 612-625.

Berinsky, A., Hutchings, V., Mendelberg, T., Shaker, L., \& Valentino, N. (2011). Sex and race: Are black candidates more likely to be disadvantaged by sex scandals? Political Behavior, 33(2), 179-202. DOI:10.1007/s11109-010-9135-8

Caruso, E.M., Mead, N.L., \& Balcetis, E. (2009). Political partisanship influences perception of biracial candidates' skin tone. Proceedings of the National Academy of Sciences of the United States of America. 106(48). 20168-20173.

Correll, J., Cloutier, J., \& Mellinger, C. (2016). Discriminating perception. Psychological Inquiry, 27(4), 281-285. DOI: 10.1080/1047840X.2016.1215209 
Deska, J.C., Lloyd, E.P., \& Hugenberg, K. (2016). Advancing our understanding of the interface between perception and intergroup relations. Psychological Inquiry, 27(4), 286-289. DOI: $10.1080 / 1047840 X .2016 .1215208$

Enos, R.D. (2016). Context, perception, and intergroup relations. Psychological Inquiry, 27(4), 294-298. DOI: 10.1080/1047840X.2016.1215218

Freeman, J.B., \& Johnson, K.L. (2016). More than meets the eye: Split-second social perception. Trends in Cognitive Sciences, 20(5), 362-374. DOI: 10.1016/j.tics.2016.03.003

Gilliam, F.D., \& Iyengar, S. (2000). Prime suspects: The influence of local television news on the viewing public. American Journal of Political Science, 44 (3), 560-573.

Hutchings, V.L., \& Valentino, N.A. (2004). The centrality of race in American politics. Annual Review of Political Science, 7, 383-408

Leyens, J., \& Yzerbyt, V. Y. (1992). The ingroup overexclusion effect: Impact of valence and confirmation on stereotypical information search. European Journal of Social Psychology, 22, 549-569.

Mendelberg, T. (2008). Racial priming revived. Exchange, 6(1), 109-123. DOI: $10.1017 / \mathrm{S} 1537592708080092$

Messing, S., Jabon, M., \& Plaut, E. (2016). Bias in the flesh: Skin complexion and stereotype consistency in political campaigns. Public Opinion Quarterly, 80(1), 44-65. doi:10.1093/poq/nfv046

Pauker, K., Weisbuch, M., Ambady, N., Sommers, S.R., \& Adams, Jr., R.B. (2009). Not so black and white: Memory for ambiguous group members. Journal of Peronality and Social Psychology. 96(4). 795-810. 
Reynolds, K.J., \& Subasic, E. (2016). "We see things not as they are, but as we are": Social identity, self-categorization, and perception. Psychological Inquiry, 27(4), 348-351. DOI: 10.1080/1047840X.2016.1215665

Stern, C., Balcetis, E., Cole, S., West, T. V., \& Caruso, E. M. (2016). Government instability shifts skin tone representations of and intentions to vote for political candidates. Journal of Personality and Social Psychology: Interpersonal Relations and Group Processes, 110(1), 76-95. doi:http://dx.doi.org.proxy.lib.pdx.edu/10.1037/pspi0000040

Swigger, N. (2012). What you see is what you get: Drawing inferences from campaign imagery. Political Communication. 29(4). 367-386.

Terkildsen, N. (1993). When white voters evaluate black candidates: The processing implications of candidate skin color, prejudice and self-monitoring. American Journal of Political Science, 37, 1032-1053

Valentino, N.A., Hutchings, V.L., \& White, I.K. (2002). Cues that matter: How political ads prime racial attitudes during campaigns. American Political Science Review, 96(1), 7590

West, T.V., Pearson, A.R., Dovidio, J.F., Johnson, B.T.J., \& Phills, C.E. (2014). Racial attitudes and visual cues in political judgments: Support for Obama during the 2008 presidential election. Cultural Diversity and Ethnic Minority Psychology, 20, 583-590. http://dx.doi.org/10.1037/ a0036947

White, I. (2007). When race matters and when it doesn't: Racial group differences in response to racial cues. American Political Science Review, 101(2), 1-16.

Xiao, Y.J., Coppin, G., \& Van Bavel, J.J. (2016). Perceiving the world through group-colored glasses: A perceptual model of intergroup relations. Psychological Inquiry, 27(4), 255- 
274. DOI: 10.1080/1047840X.2016.1199221 


\section{Appendix}

\section{Content of Online Survey}

\section{[Informed Consent]}

You are invited to participate in a web-based online survey regarding political campaigns. This is a research project being administrated by Daniel Vandehey, a student of Communication Studies at Portland State University. It should take approximately 6-8 minutes to complete.

\section{PARTICIPATION}

Your participation in this survey is voluntary. You may refuse to take part in the research or exit the survey at any time.

\section{BENEFITS}

This survey involves compensation as a Human Intelligence Task (HIT) on Amazon's mturk.com. The amount payable for completion of the task is included in the details of the HIT, and will be payable per the conditions set forth by mturk.com (https://www.mturk.com/mturk/welcome?variant=worker). Note that incomplete surveys will not be approved for payment by the administrator of this HIT.

\section{RISKS}

There are no foreseeable risks involved in participating in this study other than those encountered in dayto-day life.

\section{CONFIDENTIALITY}

Your survey answers will be sent to a link at Qualtrics.com where data will be stored in a password protected electronic format. Qualtrics does not collect identifying information such as your name, email address, or IP address. Therefore, your responses will remain anonymous. No one involved with the study will be able to identify you or your answers. The only entity with knowledge of both your participation in the survey and your identity is mturk.com, and this information is governed by contract agreement you have with mturk.com as a worker.

\section{CONTACT}

If you have questions at any time about the study or the procedures, you may contact the research supervisor, Professor Lee Shaker via email at Ishaker@pdx.edu.

If you feel you have not been treated according to the descriptions in this form, or that your rights as a participant in research have not been honored during the course of this project, or you have any questions, concerns, or complaints that you wish to address to someone other than the administrator or research supervisor, you may contact the Portland State University Institutional Review Board at :

PSU Institutional Review Board

Research Integrity, Research \& Strategic Partnerships

1600 SW 4th Ave., Market Center Building, Ste. 620

Portland, OR 97201

(503) 725-2227 or 1 (877) 480-4400 
ELECTRONIC CONSENT: Please select your choice below. You may print a copy of this consent form for your records. Clicking on the "Agree" button indicates that

- You have read the above information

- $\quad$ You voluntarily agree to participate

- You are 18 years of age or older

Agree

Disagree

Condition: Disagree Is Selected. Skip To: End of Survey.

With which gender do you self-identify?

O Female

Male

O Other

With which ethnicity do you self-identify?

O African American / Black

O American Indian

O Arab / Middle Eastern

O Asian

O Caucasian / White

O Indian

O Latina / Latino

O Pacific Islander

O Other

Age?

O 18-25

O 26-35

O $36-45$

O $46-55$

O 56-65

O 66-older

Are you registered to vote in the United States?

O Yes

O No 
Michael Bale Barnes, Ed.D, comes from a distinguished line of educators. His mother, Ekellot "Kelly" Lutaaya Barnes, was studying to become a teacher when she fled Uganda in 1972 to escape the misogynistic regime of Idi Amin. Kelly was admitted under a student visa to the University of Wisconsin, Milwaukee in 1974 where she met another student of education, Todd Barnes. Todd and Kelly married in 1977, and embarked on teaching careers within the public school system.

"The two bravest and most influential teachers in my life; my Mom and Dad." -Dr. Michael Barnes

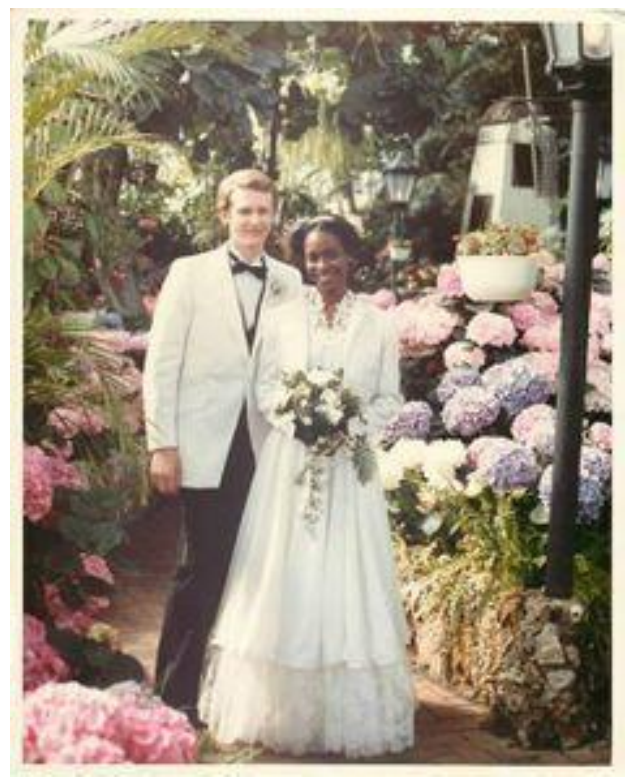

Michael was born two years later. The oldest of three children, he grew up in Racine, Wisconsin close to his paternal grandparents, who were also educators. Michael's intelligence, coupled with his access to two generations of teachers, accelerated his education. He entered the University of Wisconsin, Madison at age 16, and completed his Doctorate of Education at Pennsylvania State University in 2005. Shortly thereafter Dr. Barnes accepted a position with the Cincinnati, Ohio public school system where he advanced over an eleven year career to hold the position of Superintendent of Schools.Dr. Barnes is currently exploring the viability of a campaign for a seat in the United States Department of Education in the 2018 mid-term elections. Supporters of Dr. Barnes wish to compare his positions on major education issues with the values and concerns of the public he will be serving. This campaign will endeavor to promote education at all levels, and thus will be working with State Universities to conduct a number of online surveys. These surveys are designed to gauge the pulse of the country on public education issues, and to elicit public opinion regarding outreach and advertising strategies leading up to the election.

Would you like to continue the survey, or quit and exit?

Continue

O Quit and Exit

Condition: Quit and Exit Is Selected. Skip To: End of Survey. 
The first segment of this survey will ask for your opinions regarding six important issues currently facing the U.S. Department of Education. You will see six statements regarding these issues. Please indicate whether you agree or disagree with the statements.

\section{[Policy Questionnaire]}

The amount of time public schools are in session during a given year is too little, and the school year must be lengthened to improve the quality of American public education.

$\begin{array}{ll}\bigcirc & \text { Agree } \\ \bigcirc & \text { Disagree }\end{array}$

The average Kindergarten through twelfth-grade teacher is paid an adequate amount to compensate for their level of education and responsibilities.
Agree
Disagree

Citizens who pay more in city and/or local taxes should have better public education facilities, amenities, and programs for their children than those who pay a lesser amount.
Agree
Disagree

The multi-tiered system of graduation, which allows less academically-inclined students to graduate high school with a modified diploma, should be eliminated. All high school graduates should be held to the same standard.

Agree

Disagree

Administration deadlines should be coordinated nationally instead of being left to the discretion of each state.
O Agree
Disagree 
Fine arts should be removed from the public school curriculum and privatized as an extra-curricular activity. Such activities should not place a financial burden on the school system and should be funded in whole by families of students pursuing these interests.

$\begin{array}{ll}\bigcirc & \text { Agree } \\ \bigcirc & \text { Disagree }\end{array}$

Would you like to continue the survey, or quit and exit?

O Continue

O Quit and Exit

Condition: Quit and Exit Is Selected. Skip To: End of Survey.

\section{[Random assignment of participants to one of two conditions: (1) Aligned Policy Views, or (2)} Unaligned Policy Views.]

\section{[Conditional text displayed according to responses, Condition 1: Aligned Policy Views.]}

Display This Question:

If The amount of time public schools are in session during a given year is too little, and the schoo... Agree Is Selected

Dr. Barnes agrees that lengthening the school year will improve the quality of American public education.

\section{Display This Question:}

If The amount of time public schools are in session during a given year is too little, and the schoo... Disagree Is Selected

Dr. Barnes does not agree that lengthening the school year will improve the quality of American public education.

\section{Display This Question:}

If The average Kindergarten through twelfth-grade teacher is paid an adequate amount to compensate $f$... Agree Is Selected

He also believes teachers are well compensated for their education and effort. 


\section{Display This Question:}

If The average Kindergarten through twelfth-grade teacher is paid an adequate amount to compensate $f .$. Disagree Is Selected

He also believes teachers are not compensated well enough for their level of education and effort.

\section{Display This Question:}

If Citizens who pay more in city and/or local taxes should have better public educational facilities... Agree Is Selected

He supports the idea that people who pay more in local taxes have earned the right to better facilities, amenities, and programs for their children.

\section{Display This Question: \\ If Citizens who pay more in city and/or local taxes should have better public educational facilities... Disagree Is Selected \\ He supports equality throughout the public education system and does not support the idea that children in households of lesser economic means should receive a public education inferior to children of wealthier households.}

\section{Display This Question: \\ If The multi-tiered system of graduation, which allows less academically-inclined students to gradua... Agree Is Selected \\ Dr. Barnes believes all students should be held to the same standard, and a high school diploma should signify this single standard as it has for generations in this country.}

\section{Display This Question: \\ If The multi-tiered system of graduation, which allows less academically-inclined students to gradua... Disagree Is Selected \\ Dr. Barnes believes different students are endowed with different gifts, and each student is entitled to an education best suited to their needs and abilities. A multi-tiered diploma program facilitates these differences and encourages academically challenged students to continue their education.}

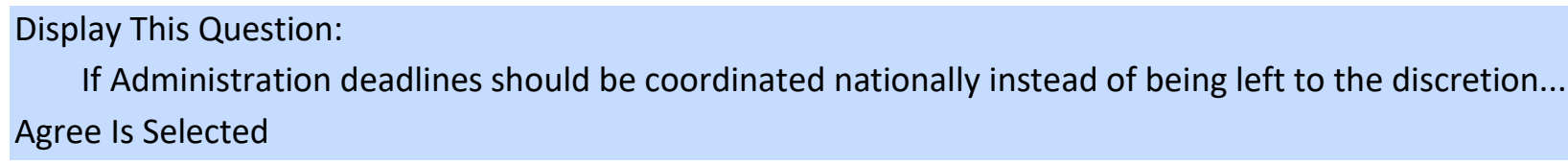

If Administration deadlines should be coordinated nationally instead of being left to the discretion... Agree Is Selected

He also opposes the national coordination of administrative deadlines, as this adds an expensive layer of bureaucracy to a system that functions well at the State level.

\section{Display This Question: \\ If Administration deadlines should be coordinated nationally instead of being left to the discretion... Disagree Is Selected}

He also supports the national coordination of administration deadlines in order to provide consistency throughout the entire U.S. public education system. 


\section{Display This Question:}

If Fine arts should be removed from the public school curriculum and privatized as an extracurricul... Agree Is Selected

Lastly, Dr. Barnes believes instruction in the fine arts lies outside the domain of any public school system, and the financial drain on public resources is not justified to accommodate the small percentage of students interested in the programs, or smaller percentage of students who go on to make a career in the arts.

\section{Display This Question:}

If Fine arts should be removed from the public school curriculum and privatized as an extracurricul... Disagree Is Selected

Lastly, Dr. Barnes believes it is the duty of the public education system to provide facilities and instruction for the fine arts, as fine arts are an indispensable facet of our society that fosters beauty and creativity in all of our lives.

\section{[Conditional text displayed according to responses, Condition 2: Unaligned Policy Views.]}

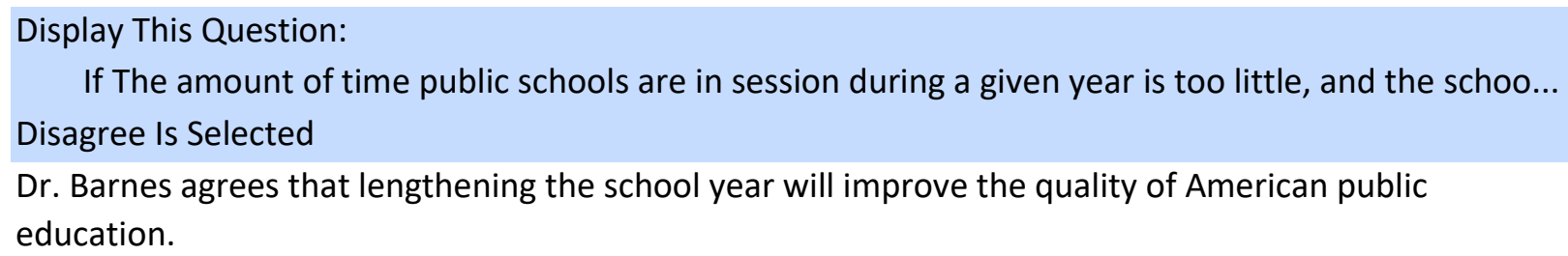

\section{Display This Question:}

If The amount of time public schools are in session during a given year is too little, and the schoo... Agree Is Selected

Dr. Barnes does not agree that lengthening the school year will improve the quality of American public education.

\footnotetext{
Display This Question:

If The average Kindergarten through twelfth-grade teacher is paid an adequate amount to compensate f... Disagree Is Selected

He also believes teachers are well compensated for their education and effort.

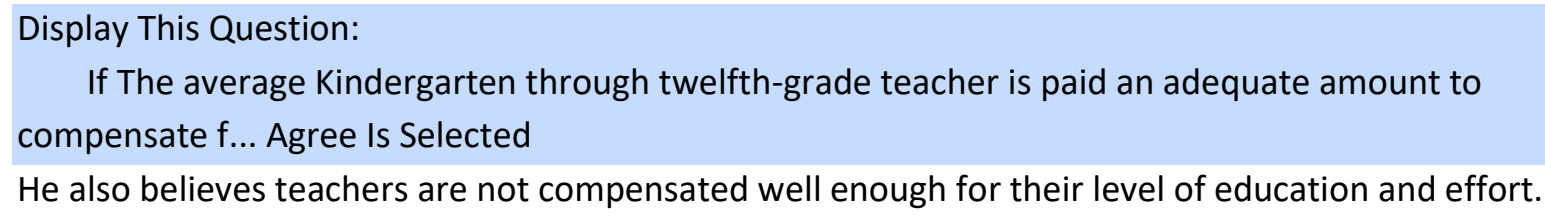




\section{Display This Question:}

If Citizens who pay more in city and/or local taxes should have better public educational facilities... Disagree Is Selected

He supports the idea that people who pay more in local taxes have earned the right to better facilities, amenities, and programs for their children.

\section{Display This Question:}

If Citizens who pay more in city and/or local taxes should have better public educational facilities... Agree Is Selected

He supports equality throughout the public education system and believes resources should be shared across all districts and tax brackets.

\section{Display This Question:}

If The multi-tiered system of graduation, which allows less academically-inclined students to gradua... Disagree Is Selected

Dr. Barnes believes all students should be held to the same standard and the issue of inferior high school diplomas devalues the document.

\section{Display This Question:}

If The multi-tiered system of graduation, which allows less academically-inclined students to gradua... Agree Is Selected

Dr. Barnes believes in multi-tiered diplomas because different students are endowed with different gifts, and each student is entitled to an education best suited to their needs and abilities.

\section{Display This Question: \\ If Administration deadlines should be coordinated nationally instead of being left to the discretion... Disagree Is Selected \\ He also opposes the national coordination of administrative deadlines, as this adds an expensive layer of bureaucracy to a system that functions well at the State level.

\author{
Display This Question: \\ If Administration deadlines should be coordinated nationally instead of being left to the discretion... \\ Agree Is Selected
}

He also supports the national coordination of administration deadlines in order to provide consistency throughout the entire U.S. public education system. 


\section{Display This Question:}

If Fine arts should be removed from the public school curriculum and privatized as an extracurricul... Disagree Is Selected

Lastly, Dr. Barnes believes instruction in the fine arts lies outside the domain of any public school system, and the financial drain on public resources is not justified to accommodate the small percentage of students interested in the programs, or smaller percentage of students who go on to make a career in the arts.

\section{Display This Question:}

If Fine arts should be removed from the public school curriculum and privatized as an extracurricul... Agree Is Selected

Lastly, Dr. Barnes believes it is the duty of the public education system to provide facilities and instruction for the fine arts, as fine arts are an indispensable facet of our society that fosters beauty and creativity in all of our lives.

\section{[Photo Selection Segment]}

In this iteration of the survey we are asking for public opinion regarding photos to use in Dr. Barnes's campaign advertising materials: including print, social media, and website exposure. Please assess each picture on its suitability to represent Dr. Barnes as a candidate for the U.S. Department of Education. You will rate the photos on a scale from Strongly Agree (the picture represents Dr. Barnes very well) to Strongly Disagree (the picture does not represent Dr. Barnes well at all).

[Represented across the following three pages is one of $\mathbf{3 6}$ possible iterations which display three poses, each with one of three skin-tones-lightened, darkened, or unaltered-presented in randomized order of both pose and skin-tone.] 


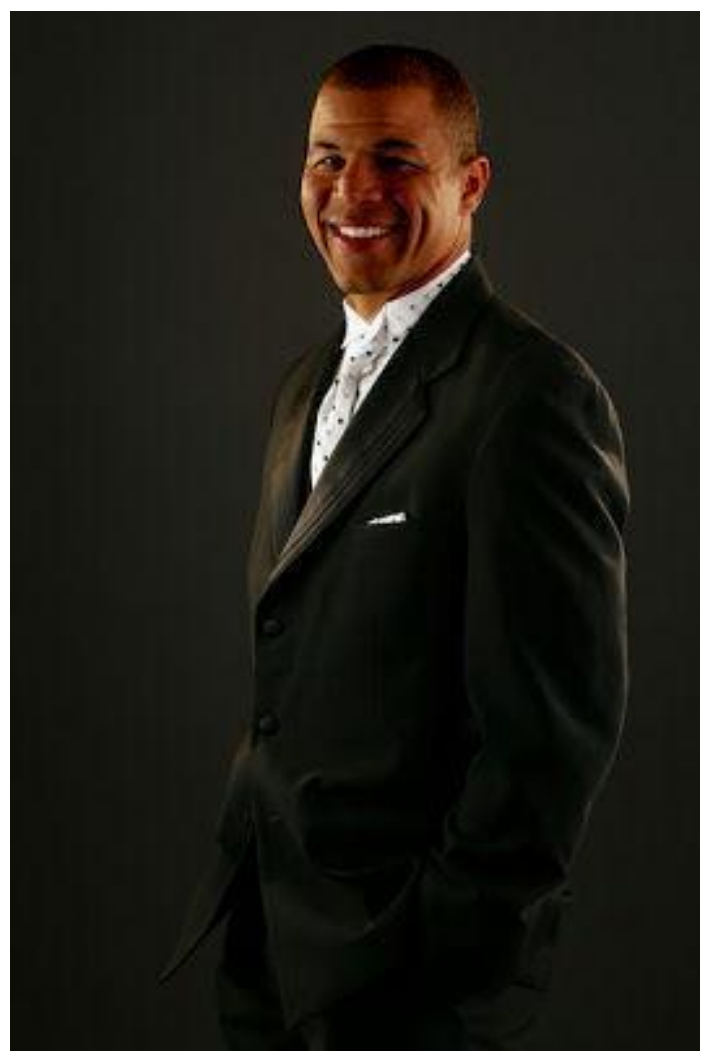

Please rate this photograph.

Strongly agree

O Agree

O Somewhat agree

Neither agree nor disagree

O Somewhat disagree

O Disagree

Strongly disagree

Would you like to continue the survey, or quit and exit?

O Continue

O Quit and Exit

Condition: Quit and Exit Is Selected. Skip To: End of Survey. 


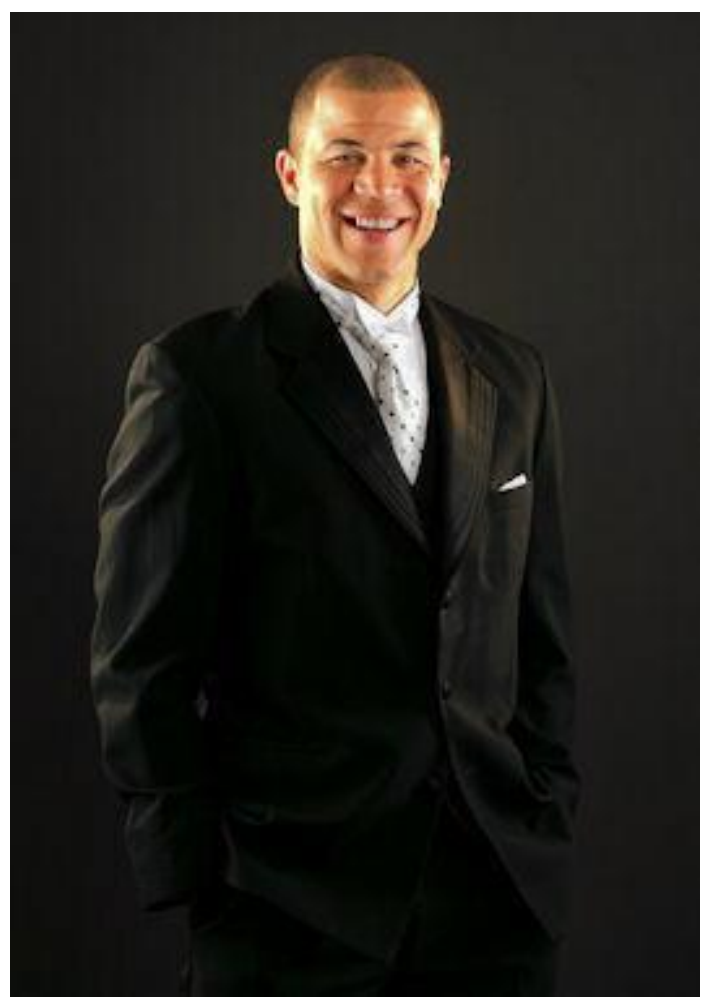

Please rate this photograph.

Strongly agree

O Agree

O Somewhat agree

Neither agree nor disagree

O Somewhat disagree

Disagree

Strongly disagree

Would you like to continue the survey, or quit and exit?

Continue

O Quit and Exit

Condition: Quit and Exit Is Selected. Skip To: End of Survey. 


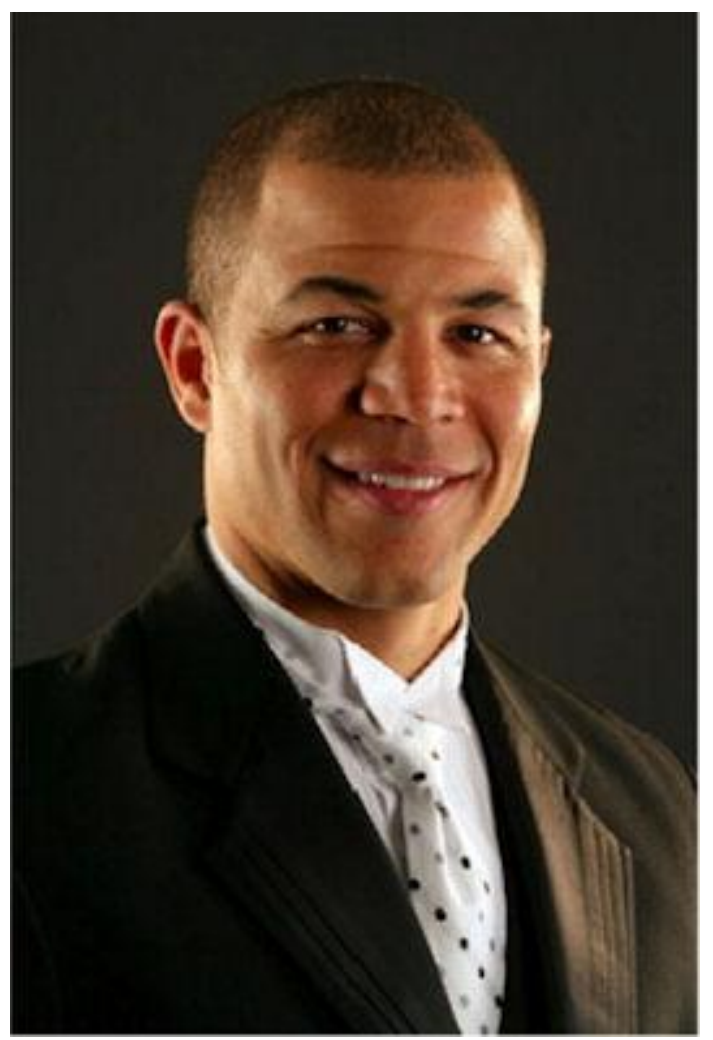

Please rate this photograph.

Strongly agree

O Agree

O Somewhat agree

Neither agree nor disagree

O Somewhat disagree

Disagree

Strongly disagree

Would you like to continue the survey, or quit and exit?

O Continue

O Quit and Exit

Condition: Quit and Exit Is Selected. Skip To: End of Survey. 


\section{[END OF SURVEY]}

You have reached the end of the survey either by completing all of the questions, or by opting-out and exiting.

If you completed the survey, your HIT will be approved soon. If you opted-out of the survey, and exited prior to completing all of the questions, your HIT will not be approved (in accordance with the informed consent form presented at the onset of the survey).

Because this study includes an element of deception, it is important that we provide information regarding the true nature of the study, which includes the survey in which you participated. If you are interested in learning more about the study, please read below.

Revealing the true nature of the study at the beginning of the survey would have made it impossible to gather the data necessary to study the target phenomena. Deception is not a tool researchers like to use, and it is only employed in cases where an alternative method cannot be constructed.

This study was designed to employ a believable scenario that included a fictitious political candidate (Dr. Barnes). 'Barnes' is the child of one white and one black parent, making his appearance racially ambiguous. You participated in one of two conditions. Either Barnes agreed with five out of six of the important educational issues, or he disagreed with five out of six. This manipulation was designed to elicit a feeling of like or dislike of the candidate based on his policy positions. Following the questionnaire regarding educational issues, you were asked to rate three images of Barnes based on how well the images represented him as a candidate. You saw three images with three different poses and three different skin tones. One of the images had been lightened, one had been darkened, and one image was unaltered. This study is looking for correlations between like or dislike of a candidate and a preference for lighter or darker skin tone in the images.

No matter how you rated the images, the most important thing to know is the results of this survey have no bearing on whether you are or are not a racist. At the implicit level we have biases about things like race, gender, weight, and a host of other attributes that make the population diverse. These implicit biases have been programmed into every person through societal and cultural pressures beginning at a very young age. We have no control over them, but we do have control over our conscious decisions to be fair and just toward all people. If you are a tolerant and kind person, the results of this survey cannot distract from your good intentions and actions.

If you would like to learn more about implicit bias, and/or take a world renowned Implicit Association Test (IAT) developed at Harvard University, please visit:

\section{https://implicit.harvard.edu/implicit/india/takeatest.html}

For the purpose of this study, the survey is designed to help determine if the implicit biases we share are the product of priming (social and cultural pressures to look at a subject in a specific way) or inclusion motivation (the desire for people we like to be more like ourselves, and people we dislike to be less like ourselves).

Your contribution to this study is important, and appreciated.

Thank you. 